\title{
Convulsant Effects of Abused Synthetic Cannabinoids JWH-018 and 5F-AB-PINACA Are Mediated by Agonist Actions at CB1 Receptors in Mice ${ }^{\mathbb{S}}$
}

\author{
Catheryn D. Wilson, Sherrica Tai, Laura Ewing, Jasmine Crane, Taylor Lockhart, \\ Ryochi Fujiwara, Anna Radominska-Pandya, and William E. Fantegrossi

\begin{abstract}
Departments of Pharmacology and Toxicology (C.D.W., S.T., L.E., J.C., T.L., W.E.F.) and Biochemistry and Molecular Biology
\end{abstract} \\ (R.F., A.R.-P.), College of Medicine, University of Arkansas for Medical Sciences, Little Rock, Arkansas
}

Received June 5, 2018; accepted November 7, 2018

\begin{abstract}
Convulsant effects of abused synthetic cannabinoid (SCB) drugs have been reported in humans and laboratory animals, but the mechanism of these effects is not known. We compared convulsant effects of partial CB1R agonist $\Delta^{9}$-tetrahydrocannabinol (THC), full CB1R agonist SCBs JWH-018 and 5F-ABPINACA, and classic chemical convulsant pentylenetetrazol (PTZ) using an observational rating scale in mice. THC did not elicit convulsions, but both SCBs did so as effectively as and more potently than PTZ. SCB-elicited convulsions were attenuated by the CB1R antagonist rimonabant or by THC, or by dose regimens of $\mathrm{THC}$ and $\mathrm{JWH}-018$, which downregulate and desensitize CB1Rs. None of these treatments altered the convulsant effects of PTZ, although diazepam attenuated PTZelicited convulsions without altering SCB-induced convulsant effects. Repeated administration of a subthreshold dose of PTZ
\end{abstract}

kindled convulsant effects, but this was not observed with the SCBs, and no cross-kindling was observed. Repeated administration of the SCBs resulted in tolerance to convulsant effects, but no cross-tolerance to PTZ was observed. Inhibition on Phase I metabolism via nonselective inhibition of CYP450s with 1-aminobenzotriazole potentiated the hypothermic effects of the SCBs and protected against the convulsant effects of JWH-018, but not those of 5F-AB-PINACA or PTZ. Incubation of human liver microsomes with the SCBs showed that $\mathrm{JWH}-018$ is eliminated via oxidation, whereas $5 \mathrm{~F}-\mathrm{AB}-$ PINACA is not. These studies suggest that SCB-elicited convulsions are mediated by high intrinsic efficacy at CB1Rs and that benzodiazepines may not be effective treatments. Finally, drug metabolism may dramatically modulate the convulsant effects of some, but not all, SCBs.

\section{Introduction}

Synthetic cannabinoids (SCBs) are structurally diverse compounds found in commercial herbal mixtures, typically marketed as "K2" or "Spice" (Seely et al., 2012, 2013). Similar to $\Delta^{9}$-tetrahydrocannabinol (THC)—-the partial cannabinoid receptor agonist and primary psychoactive constituent in marijuana-SCBs also bind to cannabinoid type-1 and -2 receptors (CB1Rs and CB2Rs). However, SCBs bind with higher affinity and intrinsic efficacy than THC (Atwood et al., 2010, 2011; Vardakou et al., 2010; Baumann et al., 2014).

This work was supported in part by the National Institutes of Health National Institute on Drug Abuse [Grants DA039143 and DA022981], by the National Institute on General Medical Sciences [IDeA Program award GM110702], by the Drug Enforcement Administration [HHSF223201610079C], and by the UAMS Translational Research Institute [RR029884]. None of the funding sources participated in study design, in the collection, analysis, and interpretation of data, in the writing of the report, or in the decision to submit the article for publication.

https://doi.org/10.1124/jpet.118.251157.

S This article has supplemental material available at jpet.aspetjournals.org.
Abuse of SCBs is associated with more frequent and severe adverse effects than those associated with cannabis use (Tait et al., 2016; Ford et al., 2017), including potentially life-threatening acute kidney injury (Bhanushali et al., 2013; Centers for Disease Control and Prevention (CDC), 2013), cardiovascular toxicity (Young et al., 2012; Varga et al., 2015), ischemia and stroke (Takematsu et al., 2014; Rose et al., 2015), and seizures and convulsions (Lapoint et al., 2011; Schneir and Baumbacher, 2012; Schep et al., 2015). With regard to these later effects, seizures and convulsions are distinct and separable phenomena. A seizure is characterized by abnormal electrical activity in the brain, which can be provoked (i.e., drug induced) or unprovoked (i.e., epilepsy) (Goldenberg, 2010; Ghofrani, 2013; Chen et al., 2016), and requires electroencephalography to diagnose and confirm (King et al., 1998; Pohlmann-Eden and Newton, 2008; Askamp and van Putten, 2013). Seizures can manifest physically in various outward signs that include, but are not limited to, readily observable convulsions (Bromfield et al., 2006). Importantly, convulsions are not exclusively associated

ABBREVIATIONS: ANOVA, analysis of variance; CB1Rs, CB1 cannabinoid receptors; CB2Rs, CB2 cannabinoid receptors; EEG, electroencephalography; 5F-AB-PINACA, N-[(2S)-1-amino-3-methyl-1-oxobutan-2-yl]-1-(5-fluoropentyl)indazole-3-carboxamide; JWH-018, 1-pentyl-3-(1-naphthoyl)indole; PTZ, pentylenetetrazole; rimonabant, 5-(4-chlorophenyl)-1-(2,4-dichloro-phenyl)-4-methyl- $N$-(piperidin-1-yl)-1H-pyrazole-3-carboxamide; SCB, synthetic cannabinoid; THC, $\Delta^{9}$-tetrahydrocannabinol; rimonabant, 5-(4-chlorophenyl)-1-(2,4-dichloro-phenyl)-4-methyl- $N$-(piperidin-1-yl)-1Hpyrazole-3-carboxamide. 
with seizure activity (Burn et al., 1989; Naik and Chakrapani, 2009). Nevertheless, in cases of acute SCB intoxication, emergency department physicians typically administer benzodiazepines to manage convulsion, delirium, and agitation (Finkelstein et al., 2017; Monte et al., 2017; Brandehoff et al., 2018). Unfortunately, this course of treatment is not evidence based and its efficacy is unknown.

Recent attention focused on characterizing the convulsant effects of SCBs in laboratory animals. In this regard, we observed rigid posture and profound leg splay in the hind limbs, full-body twitches, and handling-induced convulsions following administration of $10 \mathrm{mg} / \mathrm{kg}$ of the "first generation" napthoylindole SCB 1-pentyl-3-(1-naphthoyl)indole (JWH018) to mice and noted that these apparent convulsant effects were blocked by prior administration of the CB1R antagonist/inverse agonist rimonabant (Marshell et al., 2014). A recent in vivo electroencephalography (EEG) study replicates these findings, demonstrating that administration of JWH-018 at a dose that elicited readily observable convulsions also induced seizure activity in the brain via agonist activity at CB1Rs (Malyshevskaya et al., 2017). The fluorinated JWH-018 analog 1-[(5-fluoropentyl)-1H-indol-3-yl]-(naphthalen-1-yl)methanone (AM-2201) also elicited seizures and convulsions in mice via a CB1R-dependent mechanism, which also involves increased glutamate release within the hippocampus (Funada and Takebayashi-Ohsawa, 2018). Although these two SCBs from the naphthoylindole family can clearly elicit seizure-like activity via their agonist actions at CB1Rs, it is unclear if SCBs from other structural families would also induce seizures and convulsions. Moreover, the acute proconvulsant effects of SCBs are not well characterized in any species in terms of dose-effect relationships or underlying pharmacological mechanisms and were not previously compared with those of a classic chemical convulsant like pentylenetetrazole (PTZ).

Differences in drug metabolism may profoundly impact the pharmacological and toxicological effects of SCBs (Tai and Fantegrossi, 2017). For example, Phase I oxidative metabolism of JWH-018 generates several metabolites that retain high affinity for and efficacy at CB1Rs, including JWH-018 $(\omega)-\mathrm{COOH}, \mathrm{JWH}-018(\omega)-\mathrm{OH}$, and the chiral JWH-018 ( $\omega-1)-\mathrm{OH}$ (Brents et al., 2011; Moran et al., 2011). Cytochrome P450 2C9 (CYP2C9) is one of the major Phase I enzymes responsible for JWH-018 metabolism, with over 35 known polymorphisms in humans (Zheng et al., 2017), several of which are clinically relevant. Among these, the CYP2C9*2 and CYP2C9*3 variants both exhibit reduced enzymatic activity (Aithal et al., 1999), suggesting that individuals carrying these variants may exhibit a differential risk profile for JWH-018-elicited toxicity, perhaps including convulsant effects. Indeed, recent in vitro enzyme kinetic assays performed with human recombinant CYP2C9 variants $(* 1, * 2$, and $* 3$ ) revealed that these genetic polymorphisms produced dramatically varying levels of biologically active JWH-018 metabolites (Patton et al., 2018). Similar effects may be obtained with other SCBs, perhaps mediated by polymorphisms in other CYP450 enzymes. The role of active Phase I metabolites of SCBs in reported convulsant effects has not been determined.

The goals of the present study were therefore to focus on readily observable and quantifiable convulsant effects to first establish dose-effect functions for the high-efficacy indole-based SCB JWH-018, the high-efficacy indazole-based SCB N-[(2S)-1-amino-3-methyl-1-oxobutan-2-yl]-1-(5-fluoropentyl)indazole-3-carboxamide (5F-AB-PINACA), the partial CB1R agonist THC, and the classic chemical convulsant PTZ. We then determined whether equally convulsant effects of JWH-018, 5F-AB-PINACA and PTZ could be attenuated by acute treatment with rimonabant, the benzodiazepine diazepam, or THC, or by dose regimens of THC or JWH-018 that similarly downregulate and desensitize CB1Rs (Tai et al., 2015). Next, we ascertained the propensity of the SCBs and PTZ to induce kindling of convulsant effects upon repeated administration and determined whether an increased sensitivity to PTZelicited convulsions also increases the convulsant effects of the SCBs. Because repeated administration of CB1R agonists typically results in tolerance to in vivo effects (Karler et al., 1984; Compton et al., 1990; Lichtman and Martin, 2005), we tested if repeated administration of the SCBs would result in tolerance to their convulsant effects and whether crosstolerance to the convulsant effects of PTZ would also develop. Finally, we investigated the contribution of active hydroxylated metabolites of the SCBs to their convulsant effects via nonselective inhibition of CYP450 enzymes in mice and assessed potential differences in elimination by oxidation between JWH-018 and 5F-AB-PINACA in human liver microsomes (HLM).

\section{Materials and Methods}

\section{Drugs}

JWH-018, THC, and diazepam were obtained from the National Institute of Drug Abuse Drug Supply Program (Bethesda, MD). 5F-AB-PINACA was purchased from Cayman Chemical (Ann Arbor, MI). Rimonabant was synthesized in the laboratory of Thomas E. Prisinzano, $\mathrm{PhD}$, at the University of Kentucky School of Pharmacy, Department of Medicinal Chemistry (Lexington, KY). PTZ and 1aminobenzotriazole 1-ABT were purchased from Sigma-Aldrich (St. Louis, MO). JWH-018, THC, and 5F-AB-PINACA were dissolved in a vehicle containing ethanol, Tween 80 , and saline at a ratio of $1: 1$ : 18. Diazepam and PTZ were dissolved in $0.9 \%$ physiologic saline. 1-ABT was dissolved in a vehicle containing saline and 5\% DMSO. All injections were administered intraperitoneally at a constant volume of $0.01 \mathrm{ml} / \mathrm{g}$.

\section{Animals}

All studies used adult male National Institutes of Health-Swiss mice and were conducted in accordance with the Guide for Care and Use of Laboratory Animals as adopted and proclaimed by the National Institutes of Health. The University of Arkansas for Medical Sciences Institutional Animal Care and Use Committee approved all animal use protocols. All efforts were taken to minimize animal suffering and reduce the number of animals used. Mice were obtained from Envigo (Indianapolis, IN), arriving at 9 weeks of age and weighing between 20 and $25 \mathrm{~g}$. All subjects were housed three animals per cage $\left(15.24 \times 25.40 \times 12.70 \mathrm{~cm}^{3}\right)$ in a temperature-controlled room in an Association for Assessment and Accreditation of Laboratory Animal Care-accredited animal facility. Room conditions were maintained at $22 \pm 2^{\circ} \mathrm{C}$ and $45 \%-50 \%$ humidity, with lights set to a 12-hour light/dark cycle. Animals were fed Laboratory Diet rodent chow (Laboratory Rodent Diet no. 5001; PMI Feeds, St. Louis, MO) ad libitum until immediately before testing. All test conditions used groups of either five or six mice, with the exception of PTZ kindling studies, which used a group of eight so that PTZ-exposed mice could then be divided into two subgroups of four for a cross-kindling test with the two SCBs. All 
mice were randomly assigned to experimental groups and were drug-naive prior to the present studies.

\section{Observational Rating of Convulsions}

Observation chambers were used to score convulsions for each mouse. Chambers consisted of a cylindrical clear glass container (diameter $10.5 \mathrm{~cm}$, height $16.5 \mathrm{~cm}$ ) sealed with a ventilated cover, providing $360^{\circ}$ of visibility of movement and ample air circulation. Observation chambers were used to score the intensity of convulsions within a 30 -min period immediately following drug treatments. Animals were assigned a convulsions intensity score at $15 \mathrm{~min}$ and at 30 min after drug administration using a 4-point observational scale (a modified version of the Racine's scale developed in the laboratory), and these two scores were summed for a total convulsion score. Operational definitions for each of the four possible scores and illustrative examples are presented in Table 1. An intensity score of 0 was assigned when normal behavior was observed for the entire 15-min interval, while a score of 1 was assigned when body rigidity, leg splay, and full body twitching were observed. A score of 2 was recorded

TABLE 1

Observational scale used to score convulsion intensity

\begin{tabular}{lc}
\hline $\begin{array}{c}\text { Intensity } \\
\text { Score }\end{array}$ & Description \\
\hline 0 &
\end{tabular}

0
Rigidity, leg splay, full body twitches

Typical mouse behavior

Rigidity, leg splay, full body twitches, and handling-elicited convulsion
Rigidity, leg splay, full body twitches,
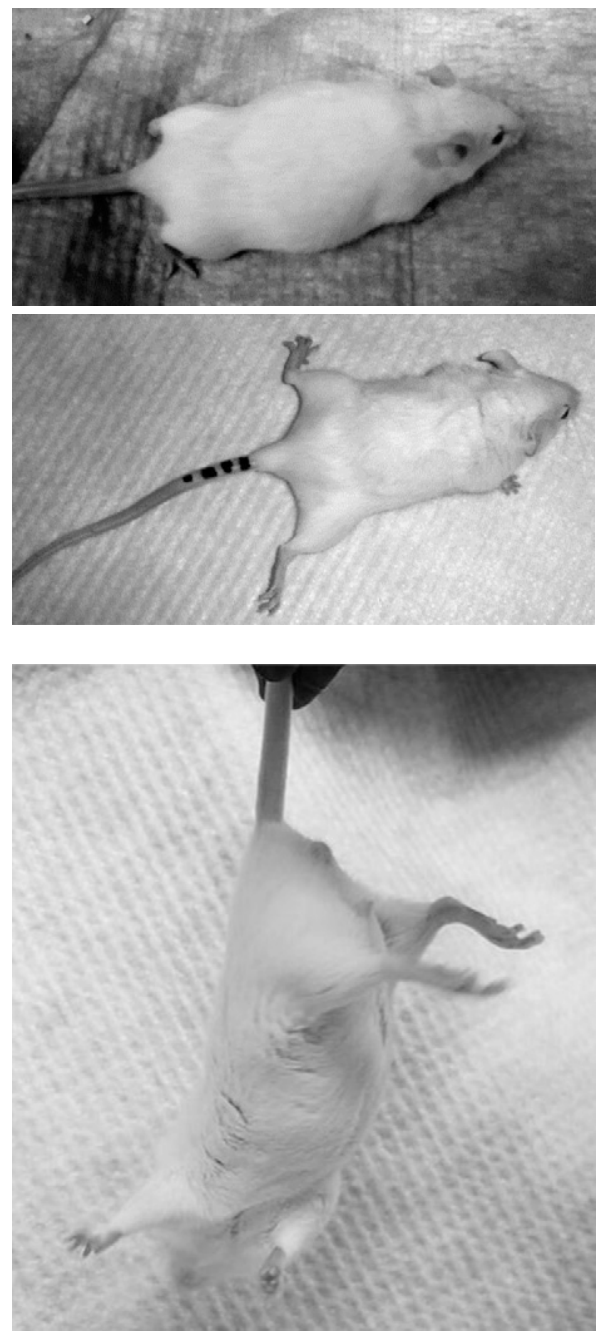
and spontaneous convulsion

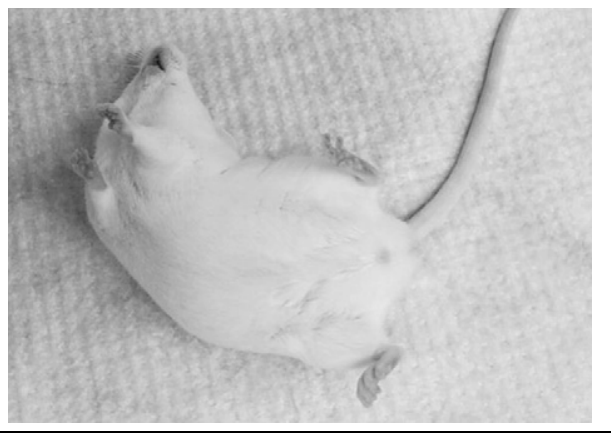


when all signs of score 1 were present along with handling-induced convulsions at the conclusion of the 15-min interval, when the experimenter tested for convulsions triggered by physical contact. In contrast, a score of 3 was recorded when an undisturbed mouse exhibited at least one full-body convulsion at any point in the 15-minute scoring interval. Depending on the drug and dose administered, convulsant effects reliably progressed from 0 to 1 , but then progressed to either 2 or 3 . We never observed a 1-2-3 progression.

\section{Experimental Design of Convulsion Studies}

Dose-Effect Studies. In the dose-effect studies of convulsant effects, mice ( $n=5$ /group; total of 70 mice) were intraperitoneally injected with either saline, cannabinoid vehicle, JWH-018 (3, 5.6, $10 \mathrm{mg} / \mathrm{kg}$ ), 5F-AB-PINACA (3, 5.6, $10 \mathrm{mg} / \mathrm{kg})$, PTZ (30, 40, $50 \mathrm{mg} / \mathrm{kg}$ ), or THC $(30,56,100 \mathrm{mg} / \mathrm{kg})$ and immediately placed into observation chambers. All subjects were evaluated for 30 min using the observational convulsion rating scale described above.

Acute Pretreatment Studies. In the acute pretreatment studies, mice ( $n=5$ /group; total of 85 mice) were pretreated with either saline, $10 \mathrm{mg} / \mathrm{kg}$ rimonabant, $3 \mathrm{mg} / \mathrm{kg}$ diazepam, or THC (3 and $10 \mathrm{mg} / \mathrm{kg}$ ). Mice were immediately returned to their home cage for a 30-min pretreatment period, then injected with equally effective convulsant doses of JWH-018 (10 mg/kg), 5F-AB-PINACA $(10 \mathrm{mg} / \mathrm{kg})$, or PTZ $(50 \mathrm{mg} / \mathrm{kg})$, determined from the previous dose-effect studies. Convulsions were then scored identically as described above.

Repeated Administration Studies. Previously, we reported that daily administration of $30 \mathrm{mg} / \mathrm{kg}$ THC or $3 \mathrm{mg} / \mathrm{kg}$ JWH-018 for 5 consecutive days results in similar downregulation and desensitization of CB1Rs in brain tissue drawn from treated mice 24 hours after the last injection (Tai et al., 2015). These same dose regimens were therefore administered in the present convulsion studies. Mice $(n=$ $5 /$ dose combination; total of 45 mice) were repeatedly administered with either the cannabinoid vehicle, $30 \mathrm{mg} / \mathrm{kg}$ THC, or $3 \mathrm{mg} / \mathrm{kg}$ JWH018 for consecutive 5 days. The following day, mice from each treatment group received equally effective convulsant doses of JWH018, 5F-AB-PINACA, and PTZ. Convulsions were then evaluated using the observational convulsion rating scale described previously.

Kindling Studies. In the kindling studies, repeated administration of subconvulsant doses of JWH-018 (3 mg/kg), 5F-AB-PINACA (3 mg/kg), and PTZ (40 mg/kg) were administered every $48 \mathrm{~h}$, for five total injections ( $n=5 /$ group, and $n=8 / \mathrm{PTZ}$ group; total of 18 mice). Two days after the last PTZ injection, the PTZ-treated mice were separated into subgroups of four animals each, which were then administered a single injection of JWH- 018 or $5 \mathrm{~F}-\mathrm{AB}-\mathrm{PINACA}(3 \mathrm{mg} / \mathrm{kg})$ to test for cross-kindling between PTZ and the SCBs. Convulsions were then evaluated using the observational convulsion rating scale described previously.

Tolerance Studies. In the tolerance studies, equally effective convulsant doses of JWH-018 $(10 \mathrm{mg} / \mathrm{kg})$ and 5 F-AB-PINACA $(10 \mathrm{mg} / \mathrm{kg})$ were administered every $24 \mathrm{~h}$, for five total injections, to mice $(n=$ 5/group; total of 10 mice). The day after the last SCB injection mice from each treatment group were administered a single injection of $50 \mathrm{mg} / \mathrm{kg}$ PTZ to test for cross-tolerance between the SCBs and PTZ. Convulsions were then evaluated using the observational convulsion rating scale described previously.

\section{Biotelemetry of Core Temperature}

Surgical preparation and real-time data collection using biotelemetry probes were conducted as previously described (Gannon et al., 2016). Briefly, the abdominal area of each mouse was shaved and sterilized with iodine swabs following anesthetization with inhaled isoflurane. A rostral-caudal cut approximately $1.5 \mathrm{~cm}$ in length was made with sterile skin scissors, providing access to the intraperitoneal cavity. A cylindrical glass-encapsulated radiotelemetry probe (model ER-4000 E-Mitter; Mini Mitter Co., Inc., Bend, OR) was then inserted, and the incision was closed using 5-0 absorbable suture material. Surgeries were carried out 14 days before initiation of each experiment, allowing time for incisions to heal. After surgery, all implanted mice were individually housed in $15.24 \times 25.40 \times 12.70 \mathrm{~cm}$ cages for the duration of all telemetry experiments. Implanted transmitters produced temperature-modulated signals that were sent to a receiver (model ER-4000 Receiver; Mini Mitter Co., Inc.) underneath each cage. Every $5 \mathrm{~min}$, the computer collected data updates from the probes for core temperature readings (in degrees Celsius).

\section{Experimental Design of Biotelemetry Studies}

As proof-of-principle that manipulation of Phase I metabolism would alter the in vivo effects of the SCBs, hypothermic effects of $3 \mathrm{mg} / \mathrm{kg}$ JWH-018 or 5F-AB-PINACA were determined using radiotelemetry in the presence or absence of the global CYP450 inhibitor 1-ABT in mice ( $n=6$ /group; total of 24 mice). After at least $60 \mathrm{~min}$ of baseline data collection, mice were injected with $3 \mathrm{mg} / \mathrm{kg}$ of JWH- 018 or $5 \mathrm{~F}-\mathrm{AB}$ PINACA and returned to the telemetry stage for $24 \mathrm{~h}$ of data collection. For 1 -ABT studies, $100 \mathrm{mg} / \mathrm{kg}$ 1-ABT was administered $120 \mathrm{~min}$ prior to SCB exposure, and core temperatures were recorded for $24 \mathrm{~h}$ of data collection.

\section{Oxidation of JWH-018 and 5F-AB-PINACA in Human Liver Microsomes}

The incubation mixture (30 $\mu \mathrm{l}$ of total volume) contained $50 \mathrm{mM}$ potassium phosphate buffer ( $\mathrm{pH}$ 7.4), NADPH regeneration system (1 mM NADP+, $3 \mathrm{mM}$ glucose 6-phosphate, $3 \mathrm{mM} \mathrm{MgCl}_{2} ; 1 \mathrm{U} / \mathrm{ml}$ glucose 6-phosphate dehydrogenase), $50 \mu \mathrm{g}$ pooled HLMs (Xenotech, Kansas City, KS), and $50 \mu \mathrm{M}$ JWH-018 or 5F-AB-PINACA. After incubation at $37^{\circ} \mathrm{C}$ for $90 \mathrm{~min}$, reactions were terminated by the addition of $30 \mu \mathrm{l}$ cold ethanol. Following removal of the protein by centrifugation at $12,000 \mathrm{~g}$ for $10 \mathrm{~min}$, a 5 - $\mu \mathrm{l}$ portion of the sample was subjected to ultra-performance liquid chromatography. All incubations were performed in triplicate. Parent compounds remaining were identified by the ACQUITY ultra-performance liquid chromatography system with an ultraviolet detector (Milford, MA). The mobile phases were $0.1 \%$ acetic acid (A) and $100 \%$ methanol (B), and the flow rate was $0.5 \mathrm{ml} / \mathrm{min}$ with an elution gradient of $100 \% \mathrm{~A}$ (0-0.2 $\mathrm{min})$, a linear gradient from $100 \% \mathrm{~A}$ to $25 \% \mathrm{~A}-75 \% \mathrm{~B}(0.2-5 \mathrm{~min})$, and $100 \% \mathrm{~B}$ (5-7 min). The column was re-equilibrated at initial conditions for $2.5 \mathrm{~min}$ between runs. The elution was monitored at $300 \mathrm{~nm}$. The retention times of JWH-018 and 5F-AB-PINACA were 6.13 and $4.60 \mathrm{~min}$, respectively.

\section{Experimental Design of In Vitro Drug Metabolism Experiments}

To compare the clearance of JWH-018 and 5F-AB-PINACA through oxidation, the drugs were incubated with HLMs with or without the $\mathrm{NADPH}$ regeneration system. The amount of substrate remaining after 90-min incubation in the presence of NADPH was normalized to the level of the SCB quantified after incubation without NADPH.

\section{Statistical Analyses}

For all experiments conducted, data were analyzed using SigmaPlot version 13 (San Jose, CA) and significance was set at the level of $P<$ 0.05. Data are presented as group means \pm S.E.M. Points or bars without indicators of variability indicate that the variance is contained within the data point.

\section{Convulsion Studies}

For dose-effect studies, a Kruskal-Wallis one-way analysis of variance (ANOVA) was performed followed by Dunnett's method to perform pairwise comparisons for each drug dose versus its appropriate control (saline for PTZ and the cannabinoid vehicle for JWH-018, 5F-ABPINACA, and THC). Data from acute pretreatment studies were analyzed using one-way ANOVA followed by pairwise comparisons via the Student-Newman-Keuls method. Repeated administration studies 
used Kruskall-Wallis one-way ANOVA, followed by pairwise comparisons using the Student-Newman-Keuls method to analyze convulsant effects. Convulsion data from both the kindling and tolerance studies were compared using a repeated-measures two-way ANOVA (with "drug" and "day" as factors), followed by Tukey's Honest Significant Difference (HSD) test. The effects of 1-ABT on convulsions elicited by JWH-018, 5F-AB-PINACA or PTZ were assessed using a KruskalWallis one way ANOVA, and all pairwise comparisons were assessed using Tukey's HSD test.

\section{Biotelemetry Studies}

The effects of 1-ABT on hypothermia were assessed using paired $t$ tests comparing the lowest average temperature achieved in each drug group $\left(\mathrm{E}_{\mathrm{MAX}}\right)$ alone or after administration of 1-ABT. Area under the curve for hypothermic effects of JWH-018 and 5F-AB-PINACA, with and without 1-ABT pretreatment, was calculated by plotting mean time-effect functions (without points or error bars). The mean timeeffect function plots were imported into Adobe Photoshop (version 7; San Jose, CA), and the areas where temperature dipped below $36^{\circ} \mathrm{C}$ were selected using the magic wand tool (with the tolerance set at 50). By using the histogram function, the number of pixels present in the area was determined (see Supplemental Fig. 1).

\section{Drug Metabolism Studies}

The effect of NADPH on oxidation of $50 \mu \mathrm{M}$ JWH- 018 or $5 \mathrm{~F}-\mathrm{AB}$ PINACA in human liver microsomes was compared using paired $t$ tests.

\section{Results}

Dose-Dependent Convulsant Effects of JWH-018, 5FAB-PINACA, and PTZ. Administration of saline (Fig. 1, open square) or the cannabinoid vehicle (Fig. 1, filled square) did not alter mouse behavior during the 30-min convulsion observation period, and all mice received scores of zero during both scoring intervals. The overall ANOVA comparing convulsion scores across all treatment conditions was significant $(\mathrm{H}=57.911$ with $13 \mathrm{df}, P<0.05$ ). Injection of JWH-018 (Fig. 1, filled circles) dose dependently elicited convulsions, with all mice exhibiting spontaneous convulsions during at least one scoring interval at a dose of $10 \mathrm{mg} / \mathrm{kg}$. Indeed, the mean convulsion score quantified after administration of $10 \mathrm{mg} / \mathrm{kg}$ JWH-018 was significantly greater than that following administration of the cannabinoid vehicle $\left(q^{\prime}=3.216, P<0.05\right)$. Similar dose-dependent convulsant effects of 5F-AB-PINACA (Fig. 1, open circles) were also observed, with all mice exhibiting spontaneous convulsions during at least one scoring interval at a dose of $10 \mathrm{mg} / \mathrm{kg}$. The mean convulsion score quantified after administration of $10 \mathrm{mg} / \mathrm{kg} 5 \mathrm{~F}-\mathrm{AB}-\mathrm{PINACA}$ was significantly greater than that following administration of the cannabinoid vehicle $\left(q^{\prime}=3.263, P<0.05\right)$. Interestingly, JWH-018 and $5 \mathrm{~F}$-AB-PINACA were similarly potent and effective in terms of eliciting convulsions, and no significant differences between these two cannabinoids were detected within dose. As expected, PTZ (Fig. 1, open triangles) also induced dose-dependent convulsant effects, although this drug was less potent than the two synthetic cannabinoids in this regard. All treated with $50 \mathrm{mg} / \mathrm{kg}$ PTZ exhibited spontaneous convulsions during at least one scoring interval, and the mean convulsion score quantified after administration of this dose was significantly greater than that following administration of saline $\left(q^{\prime}=3.263\right.$, $P<0.05)$. No significant convulsant effects were observed with any dose of THC (Fig. 1, filled triangles), and all mice received

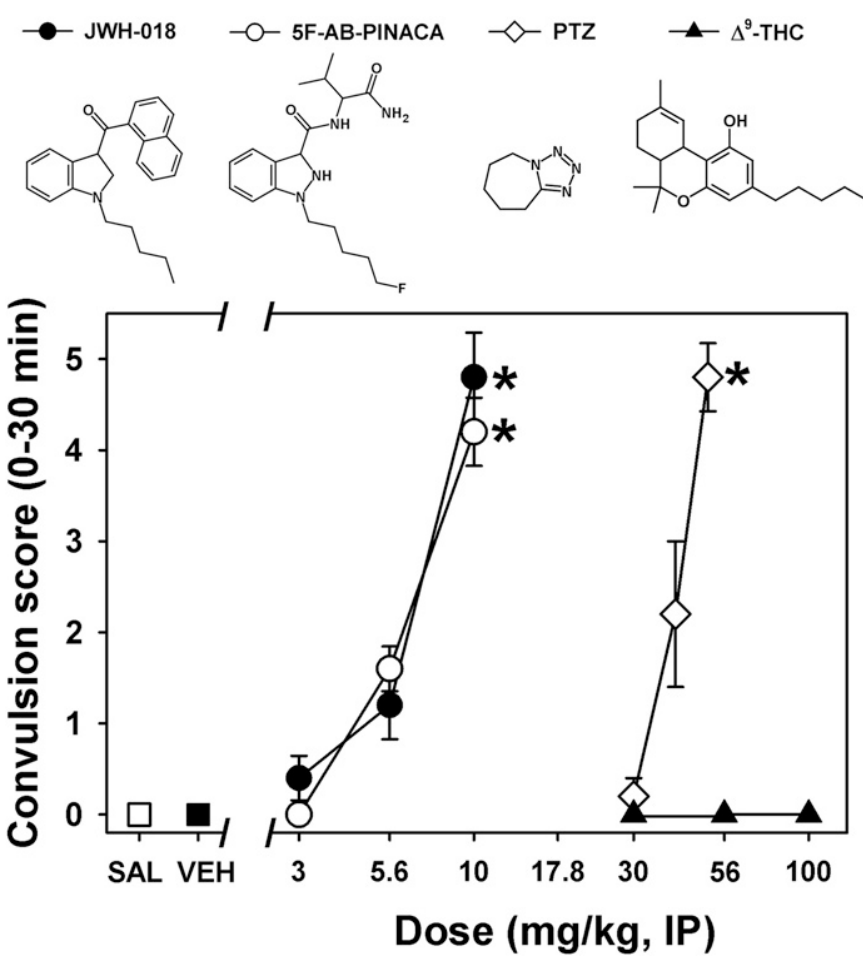

Fig. 1. Convulsant effects of saline ("SAL"; open square), cannabinoid vehicle solution ("VEH"; filled square), PTZ (open diamonds), $\Delta^{9}$-THC (filled triangles), JWH-018 (filled circles) 5F-AB-PINACA (open circles) in mice. Abscissa: convulsion score using an observational scale. Ordinate: dose of drug in milligram per kilogram on a logarithmic scale. Points represent group means, while error bars indicate \pm S.E.M. Lack of error bars indicates that the variability is contained within the point. *Significant differences from saline control (for PTZ) or from the cannabinoid vehicle control (for JWH-018 and 5F-AB-PINACA).

scores of zero during both scoring intervals, although profound sedation was noted following every administered dose.

Pharmacological Dissociation of Convulsant Effects of JWH-018 and 5F-AB-PINACA from those of PTZ. Consistent with the prior results, mice administered saline 30 min prior to injection of JWH-018, 5F-AB-PINACA, or PTZ (Fig. 2, black bars) exhibited dramatic convulsant effects. In contrast, pretreatment with $10 \mathrm{mg} / \mathrm{kg}$ of the CB1R antagonist/ inverse agonist rimonabant (Fig. 2, gray bars) significantly blocked the convulsant effects of JWH-018 $(q=16.638, P<$ $0.05)$ and 5F-AB-PINACA $(q=15.406, P<0.05)$, but did not alter the convulsant effects of PTZ $(q=1.849, P>0.05)$. However, pretreatment with $3 \mathrm{mg} / \mathrm{kg}$ of the benzodiazepine agonist diazepam (Fig. 3, open bars) significantly blocked the convulsant effects of PTZ $(q=14.173, P<0.05)$, but not those of JWH-018 $(q=1.849, P>0.05)$ or 5F-AB-PINACA $(q=1.232$, $P>0.05)$.

Acute administration of $3 \mathrm{mg} / \mathrm{kg}$ THC (Fig. 3, gray bars) 30 min prior to injection of JWH-018 or 5F-AB-PINACA significantly reduced convulsant effects $(q=5.225$ and 4.013 , respectively, $P<0.05$ for both comparisons) compared with those observed when either synthetic cannabinoid was administered without a THC pretreatment (Fig. 3, black bars.) Treatment with $10 \mathrm{mg} / \mathrm{kg}$ THC (Fig. 3, open bars) further reduced the convulsant effects of both JWH-018 and 5F-ABPINACA ( $q=6.103$ and 5.057, respectively, $P<0.05$ for both comparisons), but did not significantly alter the convulsant effects of PTZ ( $q=3.118, P>0.05)$. Because the high dose of 


\section{Pretreatment (30 min)}

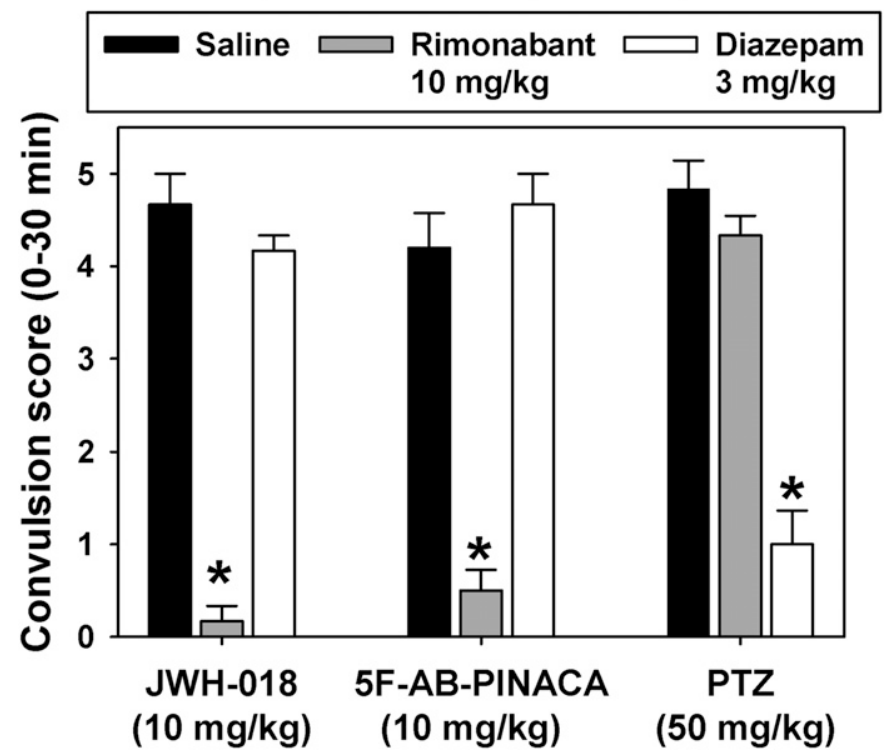

Fig. 2. Effects of saline (black bars), $10 \mathrm{mg} / \mathrm{kg}$ rimonabant (gray bars), or $3 \mathrm{mg} / \mathrm{kg}$ diazepam (open bars) on convulsions elicited by equally effective doses of JWH-018, 5F-AB-PINACA, or PTZ in mice. Abscissa: convulsion score using an observational scale. Ordinate: drug and dose used to elicit convulsions. Bars represent group means, while error bars indicate \pm S.E. M. Lack of error bars indicates that the variability is contained within the bar. *Significant differences from saline control, within drug.

THC did not protect against PTZ-elicited convulsions, the lower THC dose was not tested in the presence of PTZ.

Mice receiving daily injections of the cannabinoid vehicle (Fig. 4, black bars) for 5 consecutive days exhibited the expected convulsant effects when tested with JWH-018, 5FAB-PINACA, or PTZ 1 day after the last vehicle injection. Daily treatment with $30 \mathrm{mg} / \mathrm{kg}$ THC (Fig. 4, gray bars) significantly protected against convulsions elicited by JWH$018(q=5.482, P<0.05)$ or 5F-AB-PINACA $(q=7.044, P<$ 0.05 ) administered $24 \mathrm{~h}$ after the final THC injection. In contrast, this repeated regimen of THC did not significantly alter the convulsant effects of PTZ $(q=2.371, P>0.05)$. Similar to repeated THC exposure, mice treated daily with $3 \mathrm{mg} / \mathrm{kg}$ JWH-018 for 5 consecutive days (Fig. 4, open bars) were also significantly protected against convulsions elicited by JWH-018 ( $q=5.518, P<0.05)$ or 5F-AB-PINACA $(q=$ $7.049, P<0.05$ ) administered $24 \mathrm{~h}$ after the last pretreatment injection. Again, PTZ-elicited convulsions were not significantly attenuated by repeated treatment with JWH-018 ( $q=$ 2.574, $P>0.05)$.

Repeated Administration of Subconvulsant Doses JWH-018, 5F-AB-PINACA, and PTZ. As expected, the first administration of $3 \mathrm{mg} / \mathrm{kg}$ JWH-018 or 5F-AB-PINACA, or $40 \mathrm{mg} / \mathrm{kg}$ PTZ failed to induce observable convulsant effects (Fig. 5; left panel). Importantly, repeated administration of the two SCBs every other day never elicited convulsant effects across the treatment period. However, repeated administration of PTZ resulted in significant kindling of observable convulsions, with all PTZ-treated mice exhibiting spontaneous convulsions during at least one scoring interval after the fourth injection. Statistical testing revealed significant main effects of drug $(F=219.01, P<0.05)$ and day $(F=21.823, P<$ $0.05)$, as well as a significant interaction $(F=33.576, P<0.05)$.

\section{THC pretreatment $(\mathrm{mg} / \mathrm{kg}, 30 \mathrm{~min})$}

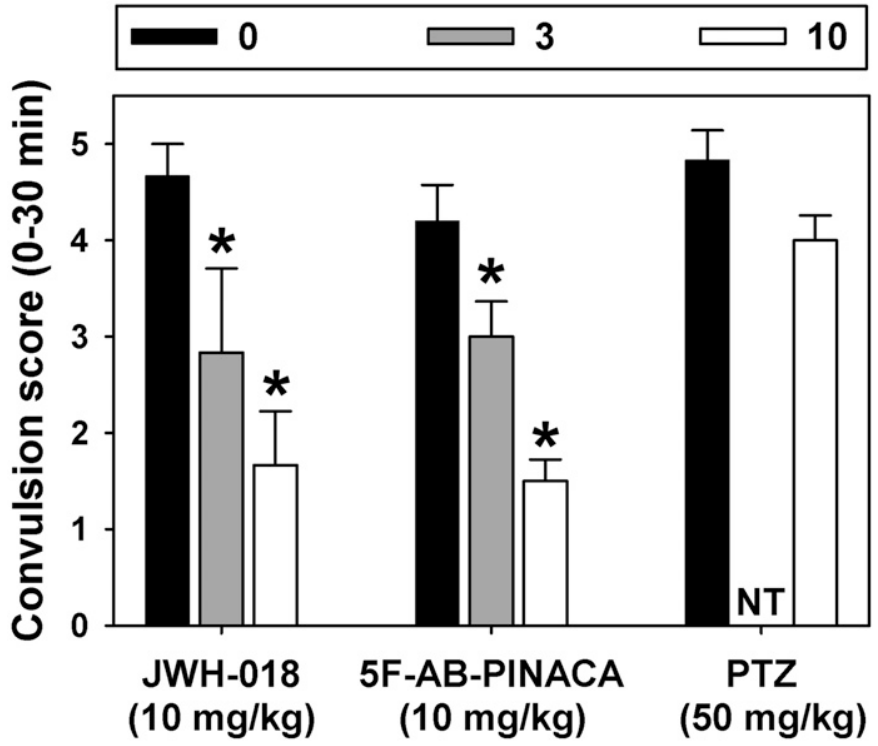

Fig. 3. Effects of no pretreatment (black bars), $3 \mathrm{mg} / \mathrm{kg}$ (gray bars), or $10 \mathrm{mg} / \mathrm{kg} \Delta^{9}$-THC (open bars) on convulsions elicited by equally effective doses of JWH-018, 5F-AB-PINACA, or PTZ in mice. Abscissa, ordinate and other graph properties as described in Fig. 2. *Significant differences from the no pretreatment control condition, within drug. NT, not tested.

Post hoc analysis indicated that the kindling observed with PTZ was a significant effect, as each drug administration elicited greater convulsant activity than observed on the previous day ( $q=9.692$ for day 2 vs. day $1, q=4.154$ for day 3 vs. day $2, q=$ 7.615 for day 4 vs. day $3, q=5.538$ for day 5 vs. day $4, P<0.05$ for all pairwise tests). In contrast, no significant differences were detected across successive injections of JWH-018 $(P>$ 0.05 for all pairwise tests) or 5F-AB-PINACA $(P>0.05$ for all pairwise tests). No observable convulsant effects were noted in PTZ-exposed mice tested with these subconvulsant doses of either SCB.

Repeated Administration of Convulsant Doses JWH018 and 5F-AB-PINACA. As expected, the initial administration of $10 \mathrm{mg} / \mathrm{kg}$ JWH-018 or $5 \mathrm{~F}-\mathrm{AB}-\mathrm{PINACA}$ again induced dramatic convulsant effects such that all mice treated with either SCB exhibited spontaneous convulsions in at least one observation period (Fig. 5; right panel). Importantly, convulsant effects were progressively blunted with repeated administration of the $\mathrm{SCBs}$, and no mice exhibited spontaneous convulsions during either scoring interval after the fourth injection. Statistical testing revealed a significant main effect of day $(F=30.43, P<0.05)$ but not of drug $(F=0.122, P>0.05)$, and the interaction was not significant $(F=0.230, P>0.05)$. Post hoc analysis indicated that tolerance to SCB-elicited convulsions was a significant effect, as each drug administration elicited lesser convulsant activity than observed on the previous day for days 1-4 for JWH-018 ( $q=4.762$ for day 2 vs. day $1, q=9.541$ for day 3 vs. day 2 , and $q=4.490$ for day 4 vs. day $3, P<0.05$ for all pairwise tests) and for 5F-AB-PINACA ( $q=5.556$ for day 2 vs. day $1, q=7.937$ for day 3 vs. day 2 , and $q=5.556$ for day 4 vs. day $3, P<0.05$ for all pairwise tests). Cross-tolerance was not evident since all mice exhibited spontaneous convulsions in at least one observation period following the test injection of PTZ. 


\section{Pretreatment (once per day $\times 5$ days)}

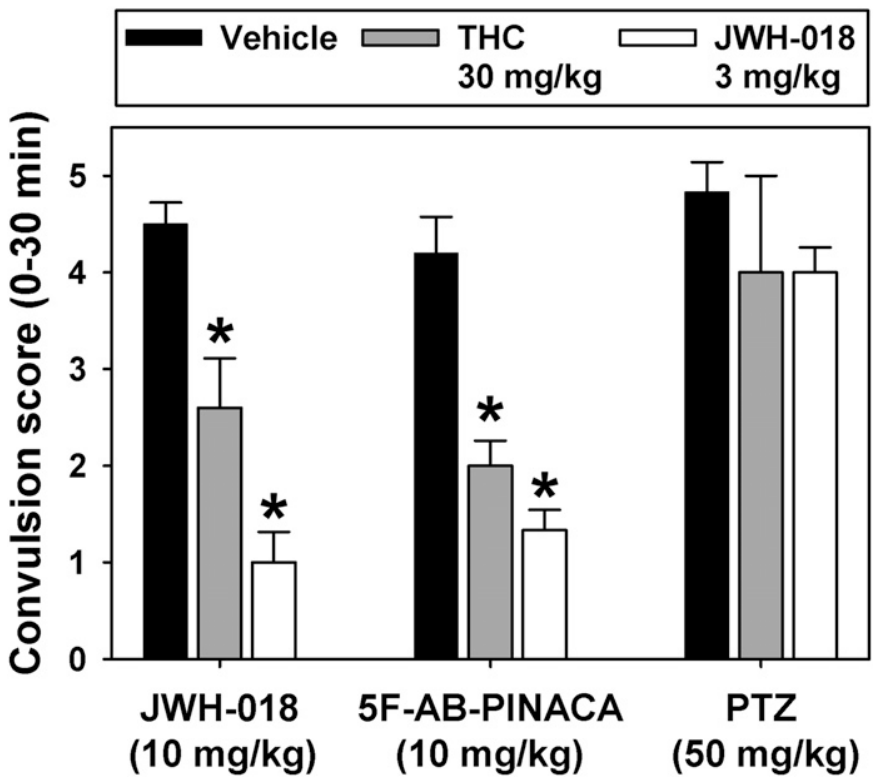

Fig. 4. Effects of daily administration of the cannabinoid vehicle (black bars), $30 \mathrm{mg} / \mathrm{kg} \Delta^{9}$-THC (gray bars), or $3 \mathrm{mg} / \mathrm{kg}$ JWH-018 (open bars) on convulsions elicited by equally effective doses of JWH-018, 5F-AB-PINACA, or PTZ in mice tested $24 \mathrm{~h}$ after the final pretreatment injection. Abscissa, ordinate and other graph properties as described in Fig. 2. *Significant differences from the cannabinoid vehicle control condition, within drug.

Involvement of Phase I Metabolism in Hypothermic and Convulsant Effects of JWH-018 and 5F-ABPINACA. In previously drug naive mice, JWH-018 induced time-dependent hypothermic effects (Fig. 6; left panel), reducing core temperature by more than $5^{\circ} \mathrm{C}$, and recovering over approximately $4 \mathrm{~h}$. Prior administration of 1 -ABT dramatically potentiated the hypothermic effects of JWH-018, such that core temperatures were reduced by approximately $9^{\circ} \mathrm{C}$, and recovered over at least $12 \mathrm{~h}$. In the presence of 1 -ABT, the area under the curve for hypothermic effects of JWH-018 increased by 6.5-fold, and the maximal hypothermic effects of JWH-018 were significantly different from those observed in mice not receiving 1 -ABT $(t=5.067$ with $4 \mathrm{df}, P<0.05$, Supplemental Fig. 1). Administration of $3 \mathrm{mg} / \mathrm{kg} 5 \mathrm{~F}-\mathrm{AB}-\mathrm{PINACA}$ to previously drug naive mice also induced time-dependent hypothermic effects, with a shorter duration of action than observed with JWH-018 (Fig. 6; right panel). Injection of 5F-AB-PINACA lowered core temperature by approximately $4^{\circ} \mathrm{C}$, and this hypothermia recovered over approximately $2 \mathrm{~h}$. As seen with JWH-018, prior administration of 1-ABT potentiated the hypothermic effects of $3 \mathrm{mg} / \mathrm{kg} 5 \mathrm{~F}-\mathrm{AB}-\mathrm{PINACA}$, reducing core temperatures by at least $8^{\circ} \mathrm{C}$ and recovering over more than $4 \mathrm{~h}$. In the presence of 1-ABT, the area under the curve for hypothermic effects increased by 6.9-fold, and the maximal hypothermic effects of 5F-AB-PINACA were significantly different from that observed in mice not receiving 1 -ABT ( $t=6.063$ with $5 \mathrm{df}, P<0.05$, see Supplemental Fig. 1). No convulsant effects of $3 \mathrm{mg} / \mathrm{kg}$ JWH-018 or 5F-AB-PINACA were observed in any mice during these biotelemetry studies, with or without 1-ABT treatment.

In stark contrast to the potentiating effects of 1-ABT on SCB-elicited hypothermia, administration of the CYP450 inhibitor $2 \mathrm{~h}$ prior to JWH-018 injection significantly decreased convulsant effects $(q=4.089, P<0.05)$ compared with vehicletreated animals (Fig. 7, left). Interestingly, 1-ABT did not alter the convulsant effects of 5F-AB-PINACA $(q=1.575, P<0.05)$ or PTZ ( $q=0.432, P<0.05$ ) (Fig. 7, left). In an effort to determine the mechanism responsible for the distinct difference in the effects of Phase I metabolism inhibition on convulsions, in vitro drug metabolism studies were employed (Fig. 7, right). Specifically, HLMs were used to determine the hepatic clearance of JWH-018 and 5F-AB-PINACA by oxidation. Phase I oxidation of JWH-018 was a substantial contributor to its hepatic metabolism, as the addition of NADPH to the incubation mixture significantly reduced the amount of
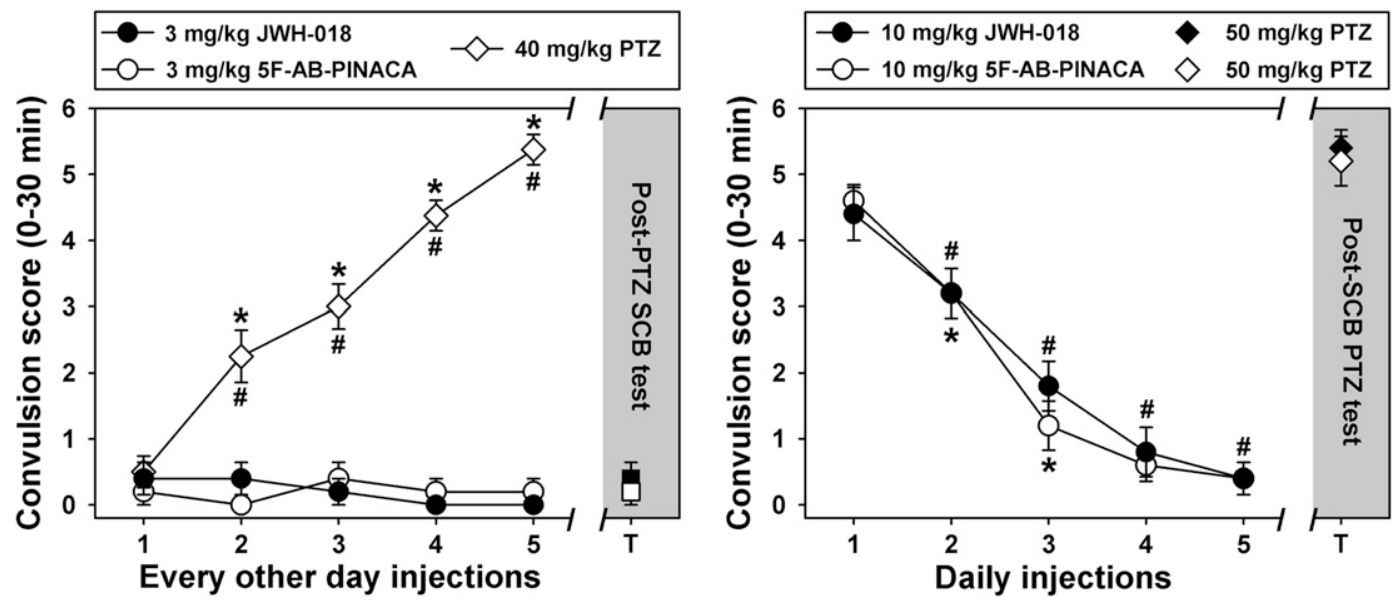

Fig. 5. (Left) Effects of administration of sub-convulsant doses of JWH-018 (3 mg/kg, filled circles), 5F-AB-PINACA (3 mg/kg, open circles), or PTZ $(40 \mathrm{mg} / \mathrm{kg}$, open diamonds) every other day for five total injections. In the gray region, the mice previously treated with PTZ were tested with $3 \mathrm{mg} / \mathrm{kg}$ JWH-018 (filled square) or $3 \mathrm{mg} / \mathrm{kg} 5 \mathrm{~F}-\mathrm{AB}$-PINACA (open square) $48 \mathrm{~h}$ after the last PTZ injection. Points represent group means, error bars represent \pm S.E.M., and all points without error bars indicate that the variability is contained within the point. *Significant differences from the previous injection (within drug); \#significant differences from SCBs (within treatment day). (Right) Effects of daily administration of convulsant doses of JWH-018 $(10 \mathrm{mg} / \mathrm{kg}$, filled circles) or $5 \mathrm{~F}-\mathrm{AB}-\mathrm{PINACA}(10 \mathrm{mg} / \mathrm{kg}$, open circles) for 5 consecutive days. In the gray region, the mice previously treated with $10 \mathrm{mg} / \mathrm{kg}$ JWH-018 (filled diamond) or $10 \mathrm{mg} / \mathrm{kg}$ 5F-AB-PINACA (open diamond) were tested with $50 \mathrm{mg} / \mathrm{kg}$ PTZ $24 \mathrm{~h}$ after their last SCB injection. Points represent group means, error bars represent \pm S.E.M. and all points without error bars indicate that the variability is contained within the point. *Significant differences from the previous injection; \#significant differences from initial drug administration (within drug). 

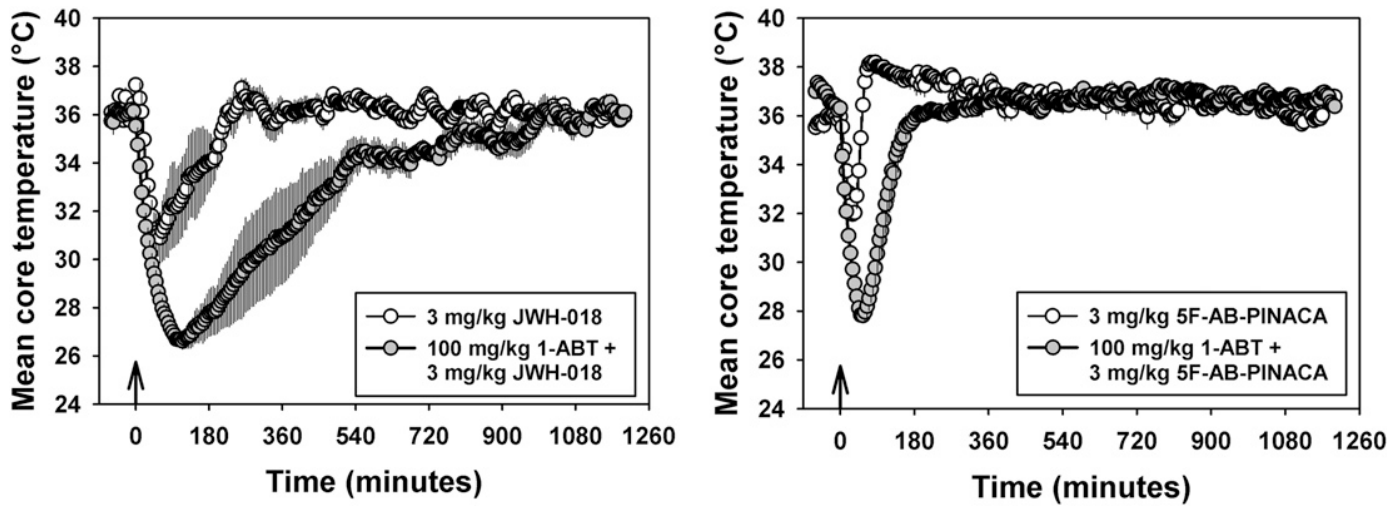

Fig. 6. Time-activity curves for hypothermic effects of $3 \mathrm{mg} / \mathrm{kg}$ JWH-018 (left) or 5F-AB-PINACA (right) alone (open circles) or $120 \mathrm{~min}$ after administration of $100 \mathrm{mg} / \mathrm{kg}$ 1-ABT (gray circles) measured via radiotelemetry. Points represent group mean, error bar represent \pm S.E.M., and all points without error bars indicate that the variability is contained within the point. Arrows indicate time of cannabinoid injection.

substrate remaining (Fig. 7A $t=19.679$ with $4 \mathrm{df}, P<0.05$ ), but this was not the case for $5 \mathrm{~F}-\mathrm{AB}-\mathrm{PINACA}$ (Fig. $7 \mathrm{~B} t=-1.947$ with $4 \mathrm{df}, P>0.05)$.

\section{Discussion}

A major finding of the present studies is that the abused high efficacy CB1R agonist SCBs, JWH-018 and 5F-AB-PINACA, potently and effectively elicited convulsant effects in mice, while THC did not. This replicates our previous observations with JWH-018 and THC (Marshell et al., 2014) and extends them to the indazole-based SCB 5F-AB-PINACA. Because the low efficacy CB1R agonist phytocannabinoid THC did not induce observable convulsions at any tested dose, and because seizure and convulsion are not typically associated with cannabis use in humans (Ford et al., 2017; but see Malyshevskaya et al., 2017 and Whalley et al., 2018) for examples of THC-elicited and cannabis extract-induced seizures, respectively, in rodents), it seems likely that high agonist efficacy at CB1R is required to elicit convulsions. Importantly, essentially all abused SCBs tested thus far exhibit greater CB1R efficacy than THC (Baumann et al., 2014; Tai and Fantegrossi, 2014; Banister et al., 2015), suggesting that use of all such illicit products carries a greater risk for convulsions than does use of cannabis. Such convulsant effects are most likely due to SCB-induced seizure-like EEG activity within the brain, although further studies are necessary to confirm this supposition.

Another central finding is that the convulsant effects of the SCBs were pharmacologically and phenomenologically dissociable from those of PTZ. Indeed, administration of rimonabant or THC effectively attenuated convulsant effects of the SCBs at doses that did not alter PTZ-induced convulsions, while treatment with diazepam abolished PTZ-elicited convulsions but afforded no protection whatsoever against convulsant effects of the SCBs. This is particularly alarming since benzodiazepine administration is the most common emergency department treatment of convulsion associated with acute SCB intoxication (Finkelstein et al., 2017; Monte et al., 2017; Brandehoff et al., 2018). Given that drug effects typically ameliorate with time, and the nature of clinical case reports describing treatment of seizure and convulsion elicited by SCBs, it is impossible to determine whether benzodiazepine administration in the emergency setting has any beneficial effects at all, and it would of course be unethical to study the possible anticonvulsant effects of benzodiazepines against an inactive placebo in individuals acutely intoxicated with SCBs.

\section{A}

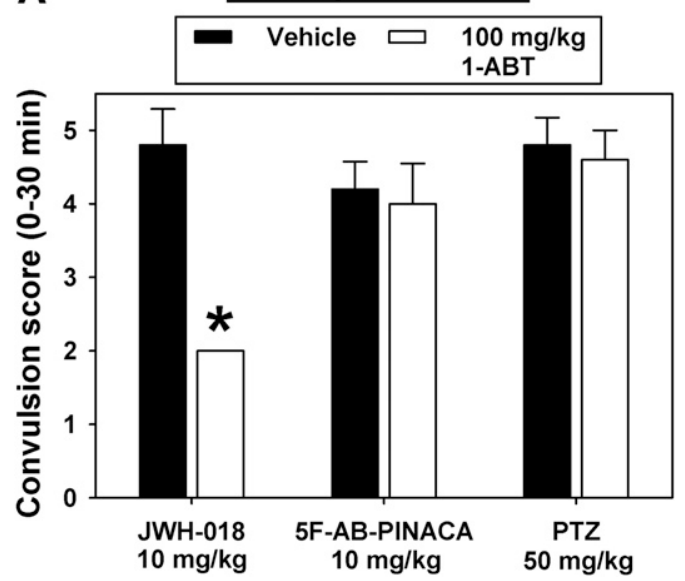

B

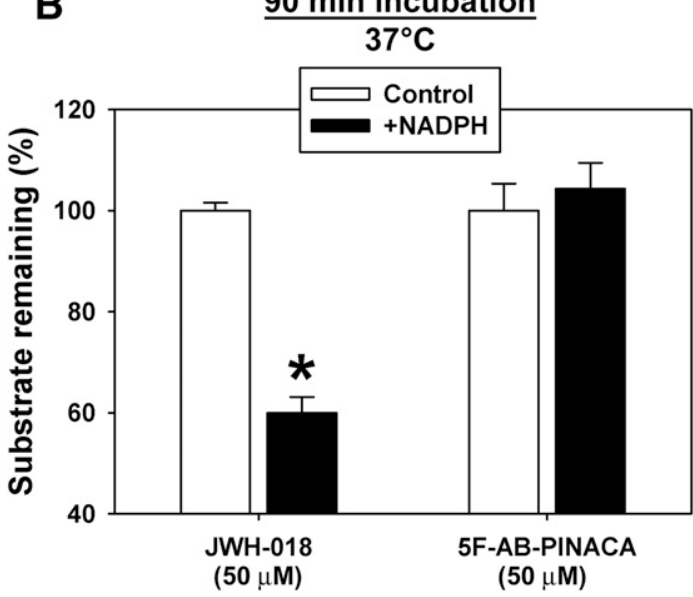

Fig. 7. (Panel A) Convulsant effects of $10 \mathrm{mg} / \mathrm{kg}$ JWH- 018 or $5 \mathrm{~F}-\mathrm{AB}-\mathrm{PINACA}$, and $50 \mathrm{mg} / \mathrm{kg}$ PTZ administered $60 \mathrm{~min}$ after vehicle (filled bars) or $120 \mathrm{~min}$ after $100 \mathrm{mg} / \mathrm{kg}$ 1-ABT injection (open bars). *Significant difference from vehicle pretreatment, within drug. (Panel B) Oxidation of $50 \mu \mathrm{M} J W H-$ 018 or 5F-AB-PINACA in human liver microsomes incubated without (open bars) or with NADPH (filled bars). *Significant difference between incubation conditions. 
However, the presently reported protective effects of rimonabant against SCB-elicited convulsions are striking, and suggest that acute treatment with CB1R antagonists might be an effective treatment strategy in human users. In this regard, rimonabant was clinically tested in the RIO-Europe trial, and a moderate adverse effects profile of nausea, dizziness, and diarrhea was initially characterized (Van Gaal et al., 2005), but a subsequent meta-analysis concluded that chronic rimonabant exposure induced serious psychiatric side effects including depression, anxiety, and suicidal ideation and action (Christensen et al., 2007). Nevertheless, acute exposure to rimonabant in the context of a limited treatment interval to reverse SCB-elicited convulsions in afflicted users may be a safe and effective therapeutic option, although more data are certainly needed to reinforce this supposition.

The studies characterizing protective effects of THC (a partial CB1R agonist) and rimonabant (a CB1R antagonist/inverse agonist) against SCB-elicited convulsions strongly suggest that the CB1R is the site of action for convulsant effects of these agents. The fact that prior exposure to doses of either THC or JWH-018 that downregulate and desensitize CB1Rs in brain tissue drawn from treated mice 24 hours after the last injection (Tai et al., 2015) also attenuate the convulsant effects of JWH018 and 5F-AB-PINACA, but not those of PTZ, also supports this notion. This perhaps challenges the utility of cannabinoidbased therapeutics in the context of epilepsy. Indeed, while drugs that increase endocannabinoid levels typically inhibit neuronal excitability and reduce epileptic seizures through CB1R activation, several direct-acting CB1R agonists have also been shown to be proconvulsant. In rats, the SCBs (11R)-2-methyl11-[(morpholin-4-yl)methyl]-3-(naphthalene-1-carbonyl)-9-oxa-1azatricyclo $\left[6.3 .1 .0^{4}{ }^{12}\right]$ dodeca-2,4(12),5,7-tetraene (WIN-55,212-2) and $N$-(2-chloroethyl)-5Z,8Z,11Z,14Z-eicosatetraenamide (arachidonyl-2'-chloroethylamide, ACEA) reduced the threshold dose of PTZ required to elicit convulsions and enhanced seizure-like EEG activity following PTZ administration, but the anandamide hydrolysis inhibitor [3-(3-carbamoylphenyl)phenyl] $N$-cyclohexylcarbamate (URB597) had the opposite effects, increasing the PTZ dose required to elicit convulsions and attenuating seizure-like EEG activity (Vilela et al., 2013). However, in mice, WIN-55,212-2 was shown to enhance the anticonvulsant effects of ethosuximide and valproic acid against PTZ-elicited convulsions by increasing the concentrations of these anticonvulsants reaching the brain via some undefined pharmacokinetic mechanism, although the coadministration of WIN-55,212-2 and PTZ significantly impaired motor coordination and long-term memory and reduced skeletal muscular strength (Luszczki et al., 2011). The present results would seem to be inconsistent with the notion that partial CB1R agonism (as produced by increased anandamide signaling) would be protective against PTZ-elicited convulsions, as neither acute THC treatment nor downregulation and desensitization of CB1Rs attenuated the convulsant effects of PTZ. So-called medical marijuana products suggested to treat epilepsy typically contain both THC and the phytocannabinoid cannabidiol (CBD), but it is perhaps important to note that CBD exhibits extremely weak affinity for CB1Rs and CB2Rs (McPartland, et al., 2007; Rosenthaler et al., 2014), although recent evidence suggests it may possess pharmacologically relevant affinity for an allosteric site on the CB2R (Martínez-Pinilla et al., 2017).

In addition to distinctions in their acute pharmacological underpinnings, convulsions elicited by the SCBs also differed from those induced by PTZ across repeated drug administrations. Injection of $40 \mathrm{mg} / \mathrm{kg}$ PTZ induced no observable convulsant effects in drug-naive mice, but repeated exposure to this dose every $48 \mathrm{~h}$ resulted in a progressive increase in convulsant effects-a phenomenon classically known as kindling (Racine et al., 1975; Coppola and Moshé, 2012; Löscher, 2017). In contrast, repeated administration of subthreshold doses of the SCBs never elicited convulsant effects across the treatment period. Importantly, mice kindled with PTZ did not exhibit an increased sensitivity to the convulsant effects of the SCBs when tested $48 \mathrm{~h}$ after the last PTZ administration. Although only a single dose of the SCBs $(3 \mathrm{mg} / \mathrm{kg})$ was used in these studies, the convulsant effects observed following the initial administration of JWH- 018 or 5F-AB-PINACA were not different from those of the first PTZ dose, suggesting perhaps a dose equivalence across these three drugs. Similarly, pharmacokinetic differences in drug disposition might have minimized kindling with the SCBs using this particular administration schedule, and a more aggressive dosing regimen (once per day, instead of every other day) might have resulted in different effects with the SCBs. That seems unlikely, however, given that daily administration of a convulsant dose $(10 \mathrm{mg} / \mathrm{kg})$ of JWH018 or 5F-AB-PINACA resulted in a progressive attenuation of convulsant effects, consistent with the commonly observed phenomenon of tolerance to cannabinoid effects in rodents (e.g., McMillan et al., 1972; Breivogel and Vaghela, 2015; Tai et al., 2015, Chopda et al., 2016). The fact that mice tolerant to the convulsant effects of the SCBs exhibited no crosstolerance whatsoever to PTZ-elicited convulsions further underscores the dramatic dissociations between convulsant effects of these compounds.

The role of Phase I metabolites in SCB-induced convulsions is complex and may vary with specific SCBs and with specific CYP450 isoforms. In the present studies, we demonstrated dramatic potentiation of hypothermic effects of JWH-018 and 5F-AB-PINACA when Phase I metabolism was inhibited with 1-ABT. Importantly, despite differences in the magnitude and duration of hypothermic effects when JWH-018 or $5 \mathrm{~F}$-AB-PINACA were administered in control mice, 1-ABT treatment resulted in lower core temperatures and increased times to recovery when either SCB was administered. Indeed, 1-ABT treatment had very similar effects on both SCBs, increasing area under the hypothermia curve for JWH-018 by a factor of 6.5 and by a factor of 6.9 for 5F-AB-PINACA. Despite this dramatic potentiation of SCB-elicited hypothermia, 1-ABT treatment did not alter the convulsant effects of $5 \mathrm{~F}-\mathrm{AB}$ PINACA, but effectively attenuated the convulsant effects of JWH-018. We (Chimalakonda et al., 2011; Moran et al., 2011) and others (Sobolevsky et al., 2010; Wintermeyer et al., 2010; Grigoryev et al., 2011) have previously described the extensive Phase I metabolism of JWH-018, resulting in several hydroxylated metabolites which retain high affinity for CB1Rs, binding with a range of efficacies, and exhibiting cannabimimetic actions in vivo (Brents et al., 2011; Chimalakonda et al., 2012). Based upon the results of the present experiments with 1-ABT, it would appear that one or more of these active Phase I metabolites are involved in the convulsant effects of JWH018. In contrast, metabolism of 5F-AB-PINACA has not been extensively studied, but one report (Wohlfarth et al., 2015) incubated human liver microsomes with 5F-AB-PINACA and identified 18 metabolites, the most abundant of which were AB-PINACA pentanoic acid and 5-hydroxypentyl-AB-PINACA. 
Our present studies with human liver microsomes were not designed to characterize specific metabolites, but simply to assess the role of oxidation in the clearance of 5F-AB-PINACA. In agreement with Wohlfarth et al. (2015), oxidation does not appear to be a significant factor in the metabolism of 5F-ABPINACA, which perhaps explains why inhibition of Phase I metabolism did not alter the convulsant effects of this particular SCB. Importantly, the sum of these experiments suggests that the convulsant effects of abused products containing SCBs would be unpredictable and highly variable across individual users given the inconstant identity of the specific compounds and doses present in these products, as well as the polymorphic nature of CYP450 enzymes across the population. Carriers of the slow-metabolizer CYP2C9*2 and CYP2C9*3 variant might be expected to experience more dramatic hypothermic effects upon use of an SCB product containing JWH-018 or 5F-ABPINACA and would be less sensitive to convulsant effects of JWH-018, but not to those of 5F-AB-PINACA, for example. This certainly highlights the unknown risks of use of illicit SCB products.

In summary, these studies established that two structurally distinct SCBs potently and effectively elicit convulsions in mice that are most likely mediated via high efficacy agonist actions at CB1Rs. A dose of diazepam that attenuates the effects of an equally convulsant dose of PTZ failed to reduce convulsions elicited by the SCBs. This suggests that common use of benzodiazepines to treat SCB-induced behavioral convulsions may not be the best therapeutic option. We further demonstrated that while the convulsant effects of PTZ kindle with repeated injection of an initially subthreshold dose, no increase in convulsant effects is observed with the SCBs. In fact, mice become tolerant to the convulsant effects of SCBs. Finally, we suggest that active Phase I metabolites contribute to the convulsant effects of some, but not all SCBs. As abuse of high efficacy SCBcontaining products continues to grow, clinical practitioners and basic scientists will need to work together to understand the unexpected toxicities elicited by these novel compounds and establish more effective treatment strategies.

\section{Acknowledgments}

We thank the UAMS Division of Laboratory Animal Medicine for expert husbandry services and Thomas Prisinzano in the Department of Medicinal Chemistry at the University of Kansas School of Pharmacy (Lawrence, KS) for providing rimonabant as a generous gift.

\section{Authorship Contributions}

Participated in research design: Wilson, Tai, Fujiwara, Radominska-Pandya, Fantegrossi.

Conducted experiments: Wilson, Tai, Ewing, Crane, Lockhart, Fujiwara.

Performed data analysis: Wilson, Tai, Fujiwara, RadominskaPandya, Fantegrossi.

Wrote or contributed to the writing of the manuscript: Wilson, Fujiwara, Radominska-Pandya, Fantegrossi.

\section{References}

Aithal GP, Day CP, Kesteven PJL, and Daly AK (1999) Association of polymorphisms in the cytochrome P450 CYP2C9 with warfarin dose requirement and risk of bleeding complications. Lancet 353:717-719.

Askamp J and van Putten MJ (2013) Diagnostic decision-making after a first and recurrent seizure in adults. Seizure 22:507-511.

Atwood BK, Huffman J, Straiker A, and Mackie K (2010) JWH018, a common constituent of 'Spice' herbal blends, is a potent and efficacious cannabinoid CB receptor agonist. Br J Pharmacol 160:585-593.

Atwood BK, Lee D, Straiker A, Widlanski TS, and Mackie K (2011) CP47,497-C8 and JWH073, commonly found in 'spice' herbal blends, are potent and efficacious CB(1) cannabinoid receptor agonists. Eur J Pharmacol 659:139-145.
Banister SD, Moir M, Stuart J, Kevin RC, Wood KE, Longworth M, Wilkinson SM, Beinat C, Buchanan AS, Glass M, et al. (2015) Pharmacology of indole and indazole synthetic cannabinoid designer drugs AB-FUBINACA, ADB-FUBINACA AB-PINACA, ADB-PINACA, 5F-AB-PINACA, 5F-ADB-PINACA, ADBICA, and 5F-ADBICA. ACS Chem Neurosci 6:1546-1559.

Baumann MH, Solis E, Jr, Watterson LR, Marusich JA, Fantegrossi WE, and Wiley JL (2014) Baths salts, spice, and related designer drugs: the science behind the headlines. J Neurosci 34:15150-15158.

Bhanushali GK, Jain G, Fatima H, Leisch LJ, and Thornley-Brown D (2013) AKI associated with synthetic cannabinoids: a case series. Clin J Am Soc Nephrol 8: $523-526$

Brandehoff N, Adams A, McDaniel K, Banister SD, Gerona R, and Monte AA (2018) Synthetic cannabinoid "Black Mamba" infidelity in patients presenting for emergency stabilization in Colorado: a P SCAN cohort. Clin Toxicol (Phila) 56:193-198.

Breivogel CS and Vaghela MS (2015) The effects of beta-arrestin1 deletion on acute cannabinoid activity, brain cannabinoid receptors and tolerance to cannabinoids in mice. J Recept Signal Transduct Res 35:98-106.

Brents LK, Reichard EE, Zimmerman SM, Moran JH, Fantegrossi WE, and Prather PL (2011) Phase I hydroxylated metabolites of the K2 synthetic cannabinoid JWH018 retain in vitro and in vivo cannabinoid 1 receptor affinity and activity. PLoS One 6:e21917.

Bromfield EB, Cavazos JE, and Sirven JI editors. An introduction to epilepsy [Internet]. West Hartford (CT): American Epilepsy Society; 2006. Chapter 2, Clinical Epilepsy. Available from: https://www.ncbi.nlm.nih.gov/books/NBK2511/.

Burn DJ, Tomson CR, Seviour J, and Dale G (1989) Strychnine poisoning as an unusual cause of convulsions. Postgraduate Medical Journal 65(766): $563-564$.

Centers for Disease Control and Prevention (CDC) (2013) Acute kidney injury associated with synthetic cannabinoid use--multiple states, 2012. MMWR Morb Mortal Wkly Rep 62:93-98.

Chen HY, Albertson TE, and Olson KR (2016) Treatment of drug-induced seizures. British Journal of Clinical Pharmacology 81(3):412-419.

Chimalakonda KC, Moran CL, Kennedy PD, Endres GW, Uzieblo A, Dobrowolski PJ, Fifer EK, Lapoint J, Nelson LS, Hoffman RS, et al. (2011) Solid-phase extraction and quantitative measurement of omega and omega-1 metabolites of JWH-018 and JWH-073 in human urine. Anal Chem 83:6381-6388.

Chimalakonda KC, Seely KA, Bratton SM, Brents LK, Moran CL, Endres GW, James LP, Hollenberg PF, Prather PL, Radominska-Pandya A, et al. (2012) Cytochrome P450-mediated oxidative metabolism of abused synthetic cannabinoids found in K2/Spice: identification of novel cannabinoid receptor ligands. Drug Metab Dispos 40:2174-2184.

Chopda GR, Parge V, Thakur GA, Gatley SJ, Makriyannis A, and Paronis CA (2016) Tolerance to the diuretic effects of cannabinoids and cross-tolerance to a $\kappa$-opioid agonist in THC-treated mice. J Pharmacol Exp Ther 358:334-341.

Christensen R, Kristensen PK, Bartels EM, Bliddal H, and Astrup A (2007) Efficacy and safety of the weight-loss drug rimonabant: a meta-analysis of randomised trials. Lancet 370:1706-1713.

Compton DR, Dewey WL, and Martin BR (1990) Cannabis dependence and tolerance production. Adv Alcohol Subst Abuse 9:129-147.

Coppola A and Moshé SL (2012) Animal models. Handb Clin Neurol 107:63-98.

Finkelstein Y, Goel G, Hutson JR, Armstrong J, Baum CR, Wax P, and Brent J; Toxicology Investigators Consortium (ToxIC) (2017) Drug misuse in adolescents presenting to the emergency department. Pediatr Emerg Care 33:451-456.

Ford BM, Tai S, Fantegrossi WE, and Prather PL (2017) Synthetic pot: not your grandfather's marijuana. Trends Pharmacol Sci 38:257-276.

Funada M and Takebayashi-Ohsawa M (2018) Synthetic cannabinoid AM2201 in duces seizures: involvement of cannabinoid $\mathrm{CB}_{1}$ receptors and glutamatergic transmission. Toxicol Appl Pharmacol 338:1-8.

Gannon BM, Williamson A, Suzuki M, Rice KC, and Fantegrossi WE (2016) Stereoselective effects of abused "Bath Salt" constituent 3,4-methylenedioxypyrovalerone in mice: drug discrimination, locomotor activity, and thermoregulation. The Journal of Pharmacology and Experimental Therapeutics 356(3):615-623.

Ghofrani M (2013) Approach to the first unprovoked seizure-PART I. Iranian Journal of Child Neurology 7(3):1-5.

Golden MM (2010) Overview of drugs used for epilepsy and seizures: etiology, diagnosis, and treatment. $P \& T$ : a peer-reviewed journal for formulatory management 35(7):392-415.

Grigoryev A, Savchuk S, Melnik A, Moskaleva N, Dzhurko J, Ershov M, Nosyrev A Vedenin A, Izotov B, Zabirova I, et al. (2011) Chromatography-mass spectrometry studies on the metabolism of synthetic cannabinoids JWH-018 and JWH-073, psychoactive components of smoking mixtures. J Chromatogr B Analyt Technol Biomed Life Sci 879:1126-1136.

Karler R, Calder LD, and Turkanis SA (1984) Changes in CNS sensitivity to cannabinoids with repeated treatment: tolerance and auxoesthesia. NIDA Res Monogr 54:312-322.

King MA, Newton MR, Jackson GD, Fitt GJ, Mitchell LA, Silvapulle MJ, and Berkovic SF (1998) Epileptology of the first-seizure presentation: a clinical, electroencephalographic, and magnetic resonance imaging study of 300 consecutive patients. Lancet 352:1007-1011.

Lapoint J, James LP, Moran CL, Nelson LS, Hoffman RS, and Moran JH (2011) Severe toxicity following synthetic cannabinoid ingestion. Clin Toxicol (Phila) 49: $760-764$.

Lichtman AH and Martin BR (2005) Cannabinoid tolerance and dependence. Handbook of Experimental Pharmacology 168:691-717.

Löscher W (2017) The search for new screening models of pharmacoresistant epilepsy: is induction of acute seizures in epileptic rodents a suitable approach? Neurochem Res 42:1926-1938.

Luszczki JJ, Andres-Mach M, Barcicka-Klosowska B, Florek-Luszczki M, Haratym-Maj A and Czuczwar SJ (2011) Effects of WIN 55,212-2 mesylate (a synthetic cannabinoid) on the protective action of clonazepam, ethosuximide, phenobarbital and valproate 
against pentylenetetrazole-induced clonic seizures in mice. Prog Neuropsychopharmacol Biol Psychiatry 35:1870-1876.

Malyshevskaya O, Aritake K, Kaushik MK, Uchiyama N, Cherasse Y, KikuraHanajiri R, and Urade Y (2017) Natural ( $\Delta^{9}$-THC) and synthetic (JWH-018) cannabinoids induce seizures by acting through the cannabinoid $\mathrm{CB}_{1}$ receptor. Sci Rep 7:10516.

Marshell R, Kearney-Ramos T, Brents LK, Hyatt WS, Tai S, Prather PL, and Fantegrossi WE (2014) In vivo effects of synthetic cannabinoids JWH-018 and JWH-073 and phytocannabinoid $\Delta^{9}$-THC in mice: inhalation versus intraperitoneal injection. Pharmacology, Biochemistry, and Behavior 124:40-47.

Martínez-Pinilla E, Varani K, Reyes-Resina I, Angelats E, Vincenzi F, Ferreiro-Vera C, Oyarzabal J, Canela EI, Lanciego JL, Nadal X, et al. (2017) Binding and signaling studies disclose a potential allosteric site for cannabidiol in cannabinoid $\mathrm{CB}_{2}$ receptors. Front Pharmacol 8:744.

McMillan DE, Ford RD, Frankenheim JM, Harris RA, and Harris LS (1972) Tolerance to active constituents of marihuana. Arch Int Pharmacodyn Ther 198:132-144.

McPartland JM, Glass M, and Pertwee RG (2007) Meta-analysis of cannabinoid ligand binding affinity and receptor distribution: interspecies differences. British Journal of Pharmacology 152(5):583-593.

Monte AA, Calello DP, Gerona RR, Hamad E, Campleman SL, Brent J, Wax P, and Carlson RG; ACMT Toxicology Investigators Consortium (ToxIC) (2017) Characteristics and treatment of patients with clinical illness due to synthetic cannabinoid inhalation reported by medical toxicologists: a ToxIC database study. $J$ Med Toxicol 13:146-152.

Moran CL, Le VH, Chimalakonda KC, Smedley AL, Lackey FD, Owen SN, Kennedy PD, Endres GW, Ciske FL, Kramer JB, et al. (2011) Quantitative measurement of JWH-018 and JWH-073 metabolites excreted in human urine. Anal Chem 83 $4228-4236$.

Naik BS and Chakrapani M (2009) A rare case of brucine poisoning complicated by rhabdomyolysis and acute renal failure. The Malaysian Journal of Pathology 31(1): $67-69$

Patton AL, Seely KA, Yarbrough AL, Fantegrossi W, James LP, McCain KR, Fujiwara R, Prather PL, Moran JH, and Radominska-Pandya A (2018) Altered metabolism of synthetic cannabinoid JWH-018 by human cytochrome P450 2C9 and variants. Biochem Biophys Res Commun 498:597-602.

Pohlmann-Eden B and Newton M (2008) First seizure: EEG and neuroimaging following an epileptic seizure. Epilepsia 49 (Suppl 1):19-25.

Racine R, Livingston K, and Joaquin A (1975) Effects of procaine hydrochloride, diazepam, and diphenylhydantoin on seizure development in cortical and subcortical structures in rats. Electroencephalogr Clin Neurophysiol 38:355-365.

Rose DZ, Guerrero WR, Mokin MV, Gooch CL, Bozeman AC, Pearson JM, and Burgin WS (2015) Hemorrhagic stroke following use of the synthetic marijuana "spice". Neurology 85:1177-1179.

Rosenthaler S, Pöhn B, Kolmanz C, Huu CN, Krewenka C, Huber A, Kranner B, Rausch WD, and Moldzio R (2014) Differences in receptor binding affinity of several phytocannabinoids do not explain their effects on neural cell cultures. Neurotoxicol Teratol 46:49-56.

Schep LJ, Slaughter RJ, Hudson S, Place R, and Watts M (2015) Delayed seizure-like activity following analytically confirmed use of previously unreported synthetic cannabinoid analogues. Hum Exp Toxicol 34:557-560.

Schneir $\mathrm{AB}$ and Baumbacher $\mathrm{T}$ (2012) Convulsions associated with the use of a synthetic cannabinoid product. $J$ Med Toxicol 8:62-64.

Seely KA, Lapoint J, Moran JH, and Fattore L (2012) Spice drugs are more than harmless herbal blends: a review of the pharmacology and toxicology of synthetic cannabinoids. Prog Neuropsychopharmacol Biol Psychiatry 39:234-243.

Seely KA, Patton AL, Moran CL, Womack ML, Prather PL, Fantegrossi WE, Radominska-Pandya A, Endres GW, Channell KB, Smith NH, et al. (2013) Forensic investigation of K2, Spice, and "bath salt" commercial preparations: a three-year study of new designer drug products containing synthetic cannabinoid, stimulant, and hallucinogenic compounds. Forensic Sci Int 233:416-422

Sobolevsky T, Prasolov I, and Rodchenkov G (2010) Detection of JWH-018 metabolites in smoking mixture post-administration urine. Forensic Sci Int 200:141-147.

Tai S and Fantegrossi WE (2014) Synthetic cannabinoids: pharmacology, behavioral effects, and abuse potential. Curr Addict Rep 1:129-136.

Tai S and Fantegrossi WE (2017) Pharmacological and toxicological effects of synthetic cannabinoids and their metabolites. Curr Top Behav Neurosci 32:249-262.

Tai S, Hyatt WS, Gu C, Franks LN, Vasiljevik T, Brents LK, Prather PL, and Fantegross WE (2015) Repeated administration of phytocannabinoid $\Delta(9)$-THC or synthetic cannabinoids JWH-018 and JWH-073 induces tolerance to hypothermia but not locomotor suppression in mice, and reduces $\mathrm{CB} 1$ receptor expression and function in a brain region-specific manner. Pharmacol Res 102:22-32.

Tait RJ, Caldicott D, Mountain D, Hill SL, and Lenton S (2016) A systematic review of adverse events arising from the use of synthetic cannabinoids and their associated treatment. Clin Toxicol (Phila) 54:1-13.

Takematsu M, Hoffman RS, Nelson LS, Schechter JM, Moran JH, and Wiener SW (2014) A case of acute cerebral ischemia following inhalation of a synthetic cannabinoid. Clin Toxicol (Phila) 52:973-975.

Van Gaal LF, Rissanen AM, Scheen AJ, Ziegler O, and Rössner S; RIO-Europe Study Group: Leizorovicz A, Danforth E, Imbs JL, Sachs D and Weintraub M (2005) Effects of the cannabinoid-1 receptor blocker rimonabant on weight reduction and cardiovascular risk factors in overweight patients: 1-year experience for the RIOEurope study. Lancet 366(9483):370.

Vardakou I, Pistos C, and Spiliopoulou Ch (2010) Spice drugs as a new trend: mode of action, identification and legislation. Toxicol Lett 197:157-162.

Varga ZV, Ferdinandy P, Liaudet L, and Pacher P (2015) Drug-induced mitochondrial dysfunction and cardiotoxicity. Am J Physiol Heart Circ Physiol 309: H1453-H1467.

Vilela LR, Medeiros DC, Rezende GH, de Oliveira AC, Moraes MF, and Moreira FA (2013) Effects of cannabinoids and endocannabinoid hydrolysis inhibition on pentylenetetrazole-induced seizure and electroencephalographic activity in rats. Epilepsy Res 104:195-202.

Whalley BJ, Lin H, Bell L, Hill T, Patel A, Gray RA, Elizabeth Roberts C, Devinsky O, Bazelot M, Williams CM, et al. (2018) Species-specific susceptibility to cannabisinduced convulsions. Br J Pharmacol DOI: 10.1111/bph.14165 [published ahead of print].

Wintermeyer A, Möller I, Thevis M, Jübner M, Beike J, Rothschild MA, and Bender $\mathrm{K}$ (2010) In vitro phase I metabolism of the synthetic cannabimimetic JWH-018. Anal Bioanal Chem 398:2141-2153.

Wohlfarth A, Castaneto MS, Zhu M, Pang S, Scheidweiler KB, Kronstrand R, and Huestis MA (2015) Pentylindole/pentylindazole synthetic cannabinoids and their 5-fluoro analogs produce different primary metabolites: metabolite profiling for AB-PINACA and 5F-AB-PINACA. AAPS $J$ 17:660-677.

Young AC, Schwarz E, Medina G, Obafemi A, Feng SY, Kane C, and Kleinschmidt K (2012) Cardiotoxicity associated with the synthetic cannabinoid, K9, with laboratory confirmation. Am J Emerg Med 30:1320.e5-1320.e7.

Zheng X, Fang P, Bao SS, Lin D, Cai JP, and Hu GX (2017) Function of 38 variants CYP2C9 polymorphism on ketamine metabolism in vitro. J Pharmacol Sci 135:8-13.

Address correspondence to: Dr. William E. Fantegrossi, Department of Pharmacology and Toxicology, College of Medicine, University of Arkansas for Medical Sciences, 4301 West Markham St., Little Rock, AR 72205. E-mail: wefantegrossi@uams.edu 